Wright, D. E. (1959). J. gen. Microbiol. 20, 554-565

\title{
The Formation of Keto and Amino Acids by Mycobacterium butyricum Growing in a Chemically Defined Medium
}

\author{
By D. E. WRIGH'T* \\ Department of Biochemistry, Medical School, University of Otago, \\ Dunedin, Nerw Zealand
}

\begin{abstract}
SUMMARY : $\alpha$-Oxoglutaric, pyruvic and amino acids accumulated extracellularly when Mycobacterium butyricum was grown in a chemically defined medium containing glycerol as carbon source and ammonium sulphate as nitrogen source. The excretion of keto acids was diminished and that of amino acids was increased by raising the concentration of ammonium sulphate relative to that of glycerol. This change is consistent with the operation of a citric acid cycle which is performing synthetic functions. The labelling of the somatic amino acids formed in the presence of glycerol and either $\left.{ }^{(14} \mathrm{C}\right)$ bicarbonate or $\left({ }^{2-14} \mathrm{C}\right)$ acetate is also consistent with the occurrence of a citric acid cycle.
\end{abstract}

Numerous investigations of the nutritional requirements of the mycobacteria have shown that the ability to use glycerol and ammonium ions as major nutrients is common to most members of the genus (see Drea \& Andrejew, 1953); Mycobacterium butyricum is no exception in this respect. Provided it is supplied with a small amount of thiamine, it grows well on a chemically defined medium in which glycerol and ammonium ions are the sole significant sources of carbon and nitrogen (Hunter, 1953). The exceptional feature of the growth of $M$. butyricum on this and on other media is the excretion of $\alpha$-oxoglutaric acid and small amounts of pyruvic and succinic acids (Hunter, 1953). By using ${ }^{14} \mathrm{C}$ tracer methods, Edson, Hunter, Kulka \& Wright (1959) found strong evidence to support the view that the $\alpha$-oxoglutaric acid excreted by $\boldsymbol{M}$. butyricum is derived from glycerol by way of the citric acid cycle and that the cycle plays an important part in both assimilation and dissimilation of glycerol. In particular, the labelling of the non-lipid carbon, including the protein-carbon, of the cells suggested that much of this carbon had passed through the cycle. The object of the present work was to study conditions under which keto acids are excreted and to investigate their relation to the synthesis of amino acids.

\section{METHODS}

Organism. Mycobacterium butyricum (no. 337) was obtained from the National Collection of Type Cultures, then at the Lister Institute, London. Flasks of medium were inoculated from culture maintained on the chemically defined medium by serial transfer every fourth day.

* Present address : Plant Chemistry Division, Department of Scientific and Industrial Research, Palmerston North, New Zealand. 
Chemically defined medium. The chemically defined medium contained (g.): $1 \cdot 0,\left(\mathrm{NH}_{4}\right)_{2} \mathrm{SO}_{4} ; 0 \cdot 2, \mathrm{NaCl} ; 0 \cdot 04, \mathrm{MgSO}_{4} 7 \mathrm{H}_{2} \mathrm{O} ; 10 \cdot 0, \mathrm{KH}_{2} \mathrm{PO}_{4} ; 0 \cdot 01$, thiamine hydrochloride; 30 glycerol (analytical reagent); distilled water to 11 . The $\mathrm{pH}$ value was adjusted to 7.5 with $3 \mathrm{~N}-\mathrm{NaOH}$ and the medium sterilized by autoclaving at $121^{\circ}$ for $15 \mathrm{~min}$.

Growth experiments. Conical flasks (500 ml.), each containing $100 \mathrm{ml}$. of medium, were inoculated with $2 \mathrm{mg}$. wet wt. of organism and incubated at $38^{\circ}$. The bacterial growth was estimated by filtering-off the pellicle on Whatman no. 1 paper, washing three times with distilled water and drying at $105^{\circ}$. For the purposes of this study the small loss of organism resulting from using this method was not significant. The culture filtrate and washings were combined and centrifuged to remove any remaining organisms.

$\mathrm{pH}$ values. All $\mathrm{pH}$ estimations were made colorimetrically with a Lovibond comparator box.

Glycerol was estimated by the method of Lambert \& Neish (1950).

$\alpha$-Oxoglutaric and pyruvic acids were measured by the method of El Hawary \& Thompson (1953); total keto acids were estimated according to Friedemann \& Haugen (1943).

Total nitrogen. Bacteria and samples of culture filtrates were digested (Hiller, Plazin \& Van Slyke, 1948) and the digest transferred to a Markham apparatus along with two drops of tributylcitrate and $1 \mathrm{ml} .10 \mathrm{~N}-\mathrm{NaOH}$. The ammonia was distilled into $10 \mathrm{ml}$. of $2 \%$ borate buffer and titrated with standard $\mathbf{H C l}$.

Free ammonia. Samples of the culture filtrates were distilled directly and titrated as above.

Amide nitrogen. Samples of culture filtrates were heated in a boiling water bath with $\mathrm{HCl}$ (final concentration of $2 \mathrm{~N}-\mathrm{HCl}$ ) for $1 \mathrm{hr}$., the solutions distilled after adding alkali and the distillate titrated. The difference in titre between this value and the free ammonia value represented amide nitrogen.

Amino nitrogen. Portions of the culture filtrates were treated with $\mathrm{HNO}_{2}$ in a micro-Van Slyke apparatus as described by Harrow et al. (1944).

Steam volatile acids. Portions of the culture filtrates were acidified and steam distilled. Carbon dioxide was removed by refluxing the distillate which on cooling was titrated with standard alkali. Acetic acid was the only acid detected in these samples by paper chromatography (Reid \& Lederer, 1952).

Chemicals. Most of the inorganic and organic chemicals were analytical reagents. Sodium $\left({ }^{14} \mathrm{C}\right)$ bicarbonate and sodium $\left(2-{ }^{14} \mathrm{C}\right)$ acetate were obtained from the Radiochemical Centre, Amersham, England.

\section{Chromatography of amino acids}

Preparation of samples. (1) Cell hydrolysates. The bacteria were defatted (Edson et al. 1959) and samples (20 mg.) of the residue hydrolysed in sealed tubes with $5 \mathrm{ml}$. of $6 \mathrm{~N}-\mathrm{HCl}$ at $100^{\circ}$ for $8 \mathrm{hr}$. The $\mathrm{HCl}$ was removed by repeated evaporation and the amino acids dissolved in $1 \mathrm{ml}$. of water. (2) Cell extracts. Samples $(50 \mathrm{mg}$.) of the dried organisms were heated with $5 \mathrm{ml}$. of distilled water in a boiling water bath for $10 \mathrm{~min}$. (Gale, 1947), the organisms 
centrifuged down and the supernatant fluid concentrated for chromatography. (3) Amino acids in culture filtrates. A portion $(50 \mathrm{ml}$.) of culture filtrate was concentrated to $10 \mathrm{ml}$. in a rotary evaporator at $30^{\circ}$ and an equal volume of cold ethanol added. After standing at $4^{\circ}$ for $1 \mathrm{hr}$., the solution was centrifuged, the supernatant fluid concentrated to $5 \mathrm{ml}$. and the process of precipitation repeated. The supernatant fluid was concentrated to a thick syrup and dissolved in $5 \mathrm{ml}$. of ethanol water $(1: 1)$. This procedure removed sufficient inorganic and protein material to give satisfactory chromatograms. The presence of glycerol sometimes distorted the spots.

Paper chromatography. The amino acids were analysed by two-dimensional paper chromatography using sec.-butanol: formic acid: water (70:10:20) as solvent for the first dimension and phenol: water: concn. ammonia (sp.gr. 0•88; $80 \mathrm{~g}$.: $20 \mathrm{ml} .: 0 \cdot 3 \mathrm{ml}$.) for the second dimension (Roberts et al. 1955). Ascending chromatography was used, the solvents reaching the top of the paper in about $16 \mathrm{hr}$. Hydrogen peroxide and ammonium molybdate were used to allow separation of methionine and valine (Dent, 1948). The chromatograms were sprayed with ninhydrin reagent. Radioautographs were prepared by placing paper chromatograms in contact with Ilford X-ray films and exposing for periods up to two months.

\section{RESULTS}

\section{The growth of Mycobacterium butyricum in the defined medium}

Little growth was observed until about the third day when the surface of the medium was covered by a thin pellicle which later became pigmented and thickened. Maximum growth was attained by the seventh to eighth day, after which the weight of organism decreased, indicating autolysis. Glycerol was consumed throughout the test period, the rate of utilization diminishing after 7 days (Fig. 1). Although growth was considerable by the fifth day, only small amounts of $\alpha$-oxoglutaric and pyruvic acids had accumulated in the medium by this time. Maximum keto acid accumulation, due mainly to $\alpha$-oxoglutaric acid, was found at 11 days. In 13 days the $\mathrm{pH}$ value of the medium fell from $7 \cdot 4$ to $5 \cdot 2$ in spite of heavy phosphate buffering (Fig. 2).

The influence of glycerol concentration. The carbon requirement of the organism was studied by varying the glycerol concentration in the range from 2 to $5 \%(\mathrm{w} / \mathrm{v})$. There was no significant effect on the yield of organism or on keto acid accumulation when the initial concentration of ammonium sulphate was either 0.05 or $0.1 \mathrm{~g} . / 100 \mathrm{ml}$. (Table 1). In Expt. 3 (Table 1) it appears that nitrogen deficiency had restricted growth but not the excretion of keto acids. On the basis of these results a glycerol concentration of $3 \%(w / v)$ was chosen for further study of keto acid formation.

The influence of ammonium sulphate concentration. Table 2 shows that increasing the ammonium sulphate concentration above $0.1 \mathrm{~g} . / 100 \mathrm{ml}$. in the presence of 3 or $4 \%(w / v)$ glycerol lead to a greater consumption of glycerol, an increased yield of organism and a striking diminution in the excretion of keto acids (cf. Table 1). The amount of keto acid which accumulated was inversely proportional to the original nitrogen content of the medium but 
directly proportional to the glycerol:ammonia ratio. The observations on the medium which originally contained $2 \%(\mathrm{w} / \mathrm{v})$ glycerol (Table 2$)$ show the same trends but are not strictly comparable because the glycerol was exhausted or almost exhausted at the end of the experiments.

The final $\mathrm{pH}$ value of the medium bore no regular relation to its initial composition or to the accumulation of keto acids.

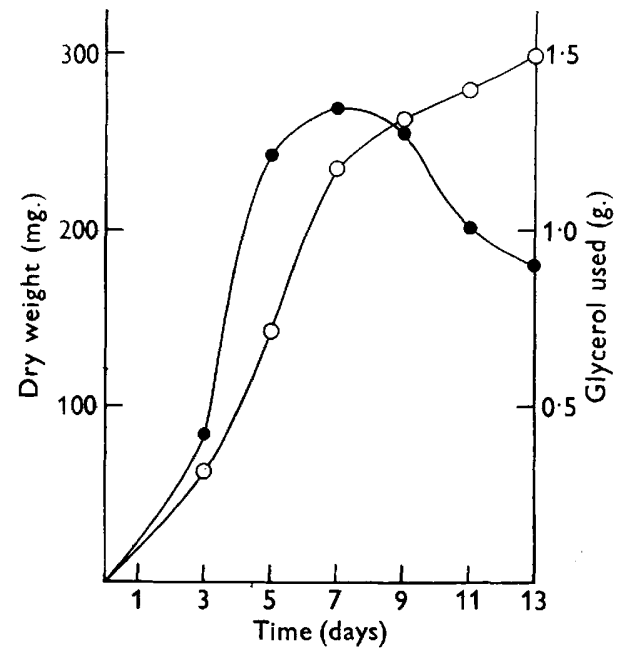

Fig. 1

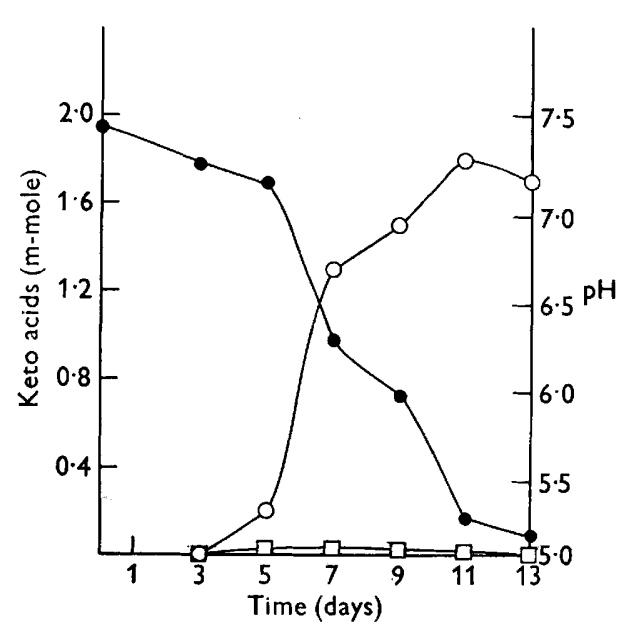

Fig. 2

Fig. 1. Growth and glycerol consumption of Mycobacterium butyricum in the defined medium.

- dry weight of organism; O, glycerol consumption.

Fig. 2. Keto acid accumulation and pH changes in the defined medium.

$\bigcirc-O, \alpha$-oxoglutaric acid; $\square-\square$, pyruvic acid.

Table 1. The effect of glycerol concentration on growth and keto acid formation by Mycobacterium butyricum

The medium (see Methods) contained 0.1 g. ammonium sulphate $/ 100 \mathrm{ml}$. in Expts. 1 and 2 and $0.05 \mathrm{~g} . / 100 \mathrm{ml}$. in Expt. 3. The inocula were taken from different mother cultures in each experiment.

\begin{tabular}{|c|c|c|c|c|c|c|}
\hline Expt. & $\begin{array}{l}\text { Time } \\
\text { (days) }\end{array}$ & $\begin{array}{c}\text { Glycerol } \\
\text { (g./100 ml.) }\end{array}$ & $\begin{array}{c}\text { Final } \\
\text { pH } \\
\text { value }\end{array}$ & $\begin{array}{c}\text { Glycerol } \\
\text { used } \\
\text { (g.) }\end{array}$ & $\begin{array}{c}\text { Bacterial } \\
\text { growth } \\
\text { (mg. dry wt.) }\end{array}$ & $\begin{array}{c}\text { Total keto } \\
\text { acid } \\
\text { (m-mole) }\end{array}$ \\
\hline \multirow[t]{3}{*}{1} & 9 & 3 & $6 \cdot 3$ & $1 \cdot 1$ & 242 & $1 \cdot 3$ \\
\hline & & 4 & $6 \cdot 4$ & 1.4 & 223 & $1 \cdot 2$ \\
\hline & & 5 & $6 \cdot 3$ & 1.7 & 238 & $\mathbf{1} \cdot \mathbf{3}$ \\
\hline \multirow[t]{3}{*}{2} & 10 & 2 & $6 \cdot 4$ & $\mathbf{I} \cdot \mathbf{I}$ & 212 & 1.5 \\
\hline & & 3 & 6.5 & $\mathbf{1} \cdot \mathbf{1}$ & 203 & $1 \cdot 3$ \\
\hline & & 4 & $6 \cdot 6$ & $1 \cdot 1$ & 202 & $1 \cdot 1$ \\
\hline \multirow[t]{3}{*}{3} & 10 & 2 & $6 \cdot 7$ & 0.8 & 140 & $1 \cdot 1$ \\
\hline & & 3 & 6.5 & $0 \cdot 9$ & 146 & $1 \cdot 2$ \\
\hline & & 4 & $6 \cdot 6$ & 1.0 & 141 & $\mathbf{1} \cdot \mathbf{3}$ \\
\hline
\end{tabular}


Table 2. The effect of varying the glycerol: nitrogen ratio

$100 \mathrm{ml}$. of medium. The ammonium sulphate was added aseptically to the sterile basal medium. Period of incubation: 10 days.

\begin{tabular}{|c|c|c|c|c|c|c|}
\hline $\begin{array}{c}\text { Glycerol } \\
\text { (g./ } \\
100 \mathrm{ml} .)\end{array}$ & $\begin{array}{c}\text { Initial } \\
\text { medium } \\
\left(\mathrm{NH}_{4}\right)_{2} \mathrm{SO}_{4} \\
(\mathrm{~g} . / 100 \mathrm{ml} .)\end{array}$ & $\begin{array}{c}\text { Glycerol : } \\
\text { ammonia-N } \\
\text { (mole) }\end{array}$ & $\begin{array}{c}\text { Final } \\
\mathrm{pH} \\
\text { value }\end{array}$ & $\begin{array}{c}\text { Glycerol } \\
\text { used } \\
\text { (g.) }\end{array}$ & $\begin{array}{l}\text { Bacterial } \\
\text { growth } \\
\text { (mg. } \\
\text { dry wt.) }\end{array}$ & $\begin{array}{c}\text { Total keto } \\
\text { acid } \\
\text { (m-mole) }\end{array}$ \\
\hline 2 & 0.20 & $7 \cdot 1$ & $6 \cdot 2$ & $2 \cdot 0$ & 358 & 0.27 \\
\hline 2 & $0 \cdot 25$ & $5 \cdot 7$ & $6 \cdot 0$ & $1 \cdot 7$ & 353 & 0.12 \\
\hline 2 & 0.30 & $4 \cdot 8$ & 6.0 & $2 \cdot 0$ & 346 & 0.04 \\
\hline 3 & $0 \cdot 15$ & $14 \cdot 3$ & $6 \cdot 1$ & $2 \cdot 2$ & 338 & 0.80 \\
\hline 3 & $0 \cdot 20$ & $10 \cdot 7$ & $6 \cdot 4$ & $2 \cdot 1$ & 358 & 0.09 \\
\hline 3 & 0.25 & $8 \cdot 6$ & $6 \cdot 4$ & $\mathbf{1 . 9}$ & 315 & 0.09 \\
\hline 3 & 0.30 & $7 \cdot 1$ & 6.2 & $2 \cdot 1$ & 347 & 0.04 \\
\hline 4 & $0 \cdot 15$ & $19 \cdot 1$ & $6 \cdot 3$ & $2 \cdot 4$ & 348 & 0.99 \\
\hline 4 & 0.20 & $14 \cdot 3$ & $6 \cdot 3$ & $2 \cdot 4$ & 395 & 0.52 \\
\hline 4 & 0.25 & $11 \cdot 4$ & $5 \cdot 9$ & $2 \cdot 1$ & 379 & $0 \cdot 17$ \\
\hline 4 & $0 \cdot 30$ & $9 \cdot 5$ & $6 \cdot 1$ & $2 \cdot 1$ & 371 & 0.04 \\
\hline
\end{tabular}

\section{Nitrogen balance}

Since $\alpha$-oxoglutaric acid is formed from glycerol, its accumulation in a medium with a high initial glycerol:ammonia ratio and its absence from a medium with a lower ratio might be explained by the effect of available nitrogen on amino acid synthesis. This possibility was explored by constructing nitrogen balance sheets for media containing $3 \cdot 0 \mathrm{~g}$. glycerol $/ 100 \mathrm{ml}$. and different amounts of ammonium sulphate. The ammonia added is expressed as $\mu$-atom $\mathrm{N} / 100 \mathrm{ml}$. of medium and to facilitate description the levels of nitrogen have been designated 1 to 6 in order of increasing quantity (Table 3). The recovery of nitrogen was satisfactory (98-102\%).

At nitrogen levels below 4 the ammonia was exhausted, growth was restricted and the nitrogen content of the organisms was low. At level 4 the organisms appeared to have attained maximum growth and nitrogen content. At level 1 the glycerol consumption was $0.9 \mathrm{~g}$.; at all other levels it was $1.6 \mathrm{~g}$.

Less than half the ammonia used at levels 4,5 and 6 reappeared as cellnitrogen. Above level 2, the residual medium contained amino nitrogen which increased with the amount of ammonia consumed. The small amount of protein released into the medium cannot account for this amino nitrogen. Amide nitrogen was not detected in any of the media. The nitrogen fraction designated 'other forms' includes protein (cf. Edson et al. 1959) and peptide nitrogen and unidentified nitrogen compounds.

Keto acids were present in all the residual media, the quantity being greatest where little or no ammonia remained (Table 3 ). The $\mathrm{pH}$ value was 6.8 at nitrogen level 1 and 6.5 at the other levels. The excretion of $\alpha$-oxoglutaric acid was high at level 1 in spite of restricted growth, reached a maximum at level 2 and was completely absent at levels 5 and 6. Pyruvic acid accumulated to the greatest degree at level 4. The inverse relationship between the keto acid and amino nitrogen content of the various media could be explained 
if the keto acids were replaced by amino acids, especially glutamic acid, as the supply of nitrogen was increased. Such a phenomenon could be consistent with a relatively constant terminal $\mathrm{pH}$ value.

Table 3. Nitrogen balance studies

$100 \mathrm{ml}$. of medium containing 3.0 g. glycerol. Period of incubation: 11 days.

\begin{tabular}{|c|c|c|c|c|c|}
\hline $\begin{array}{l}\text { Nitrogen } \\
\text { level }\end{array}$ & $\begin{array}{c}\text { Ammonia-N } \\
\text { added } \\
(\mu \text {-atom })\end{array}$ & $\begin{array}{c}\text { Bacterial-N } \\
(\mu \text {-atom })\end{array}$ & $\underset{(\mu \text {-atom })}{\operatorname{Ammonia-N}}$ & $\begin{array}{c}\text { Amino-N } \\
(\mu \text {-atom })\end{array}$ & $\begin{array}{c}\text { Other forms* } \\
\text { of } \mathrm{N} \\
(\mu \text {-atom })\end{array}$ \\
\hline 1 & 362 & 307 & 0 & 0 & 55 \\
\hline 2 & 722 & 607 & $\mathbf{0}$ & 0 & 115 \\
\hline 3 & 1,448 & 992 & o & 93 & 363 \\
\hline 4 & 2,896 & 1,372 & 86 & 558 & 880 \\
\hline 5 & 5,772 & 1,363 & 2,700 & 672 & 1,037 \\
\hline 6 & 11,584 & 1,336 & 8,440 & 736 & 1,072 \\
\hline $\begin{array}{l}\text { Nitrogen } \\
\text { level }\end{array}$ & $\begin{array}{c}\alpha \text {-Oxoglutaric } \\
\text { acid } \\
(\mu \text { mole })\end{array}$ & $\begin{array}{c}\text { Pyruvic } \\
\text { acid } \\
(\mu \text { mole })\end{array}$ & $\begin{array}{l}\text { Growth } \\
\text { (mg. dry } \\
\text { wt.) }\end{array}$ & $\begin{array}{l}\text { Cell-N } \\
\text { (\% dry } \\
\text { wt.) }\end{array}$ & $\begin{array}{c}\text { N-recovery } \\
(\%)\end{array}$ \\
\hline 1 & 870 & 0 & 86 & $5 \cdot 0$ & 99 \\
\hline 2 & 1,650 & 120 & 174 & 4.9 & 102 \\
\hline $\mathbf{3}$ & 470 & 210 & 229 & $6 \cdot 1$ & 100 \\
\hline 4 & 90 & 560 & 270 & $7 \cdot 1$ & 99 \\
\hline 5 & 0 & 90 & 279 & $6 \cdot 9$ & 99 \\
\hline 6 & 0 & 80 & 260 & $7 \cdot 2$ & 98 \\
\hline
\end{tabular}

* Calculated by difference.

Note. In relating these results to those of Table 2 it may be noted that $0.2 \mathrm{~g}$. of $\left(\mathrm{NH}_{4}\right)_{2} \mathrm{SO}_{4} /$ $100 \mathrm{ml}$. is equivalent to $3030 \mu$-atoms $\mathrm{N} / 100 \mathrm{ml}$.

\section{Synthesis of amino acids at different levels of nitrogen supply}

Hydrolysates of organisms. The organism was grown for 11 days in media containing $3.0 \mathrm{~g}$. glycerol $/ 100 \mathrm{ml}$. and ammonium sulphate at the nitrogen levels 2, 3 and 5 of Table 3. The washed, defatted organisms (see Methods) were subjected to acid hydrolysis and the amino acids, derived chiefly from the somatic proteins, analysed by paper chromatography. The amino acids identified were aspartic acid, glutamic acid, diaminopimelic acid, serine, glycine, threonine, alanine, lysine, tyrosine, methionine, arginine, proline, valine, leucine +isoleucine and phenylalanine. There were no qualitative differences in the amino acid composition of organisms grown at the different nitrogen levels.

Extracts of organisms. The free amino acids extracted from washed organisms by hot water were also examined. Organisms grown for 11 days at low nitrogen levels ( 1 and 2 of Table 3) released traces of glutamic acid, glycine, alanine and unidentified material giving two ninhydrin-reacting spots. At higher nitrogen levels the quantities of these three amino acids were increased and additional spots due to lysine, aspartic acid, methionine, valine and arginine were observed.

Culture filtrates. No amino acids were detected by paper chromatography in culture filtrates at the three lower nitrogen levels of Table 3. At level 4 
glutamic acid, lysine, valine and leucine +isoleucine were present in the medium; at the higher nitrogen levels glycine, alanine, methionine and arginine appeared in addition. In all the positive samples glutamic acid was present in considerably greater amounts than the other amino acids.

\section{Effect of adding sodium acetate to the medium}

Although washed suspensions of Mycobacterium butyricum oxidize acetate easily (Hunter, 1953), the organism does not grow to a significant extent in a medium in which acetate is the sole carbon source (Edson \& Hunter, 1943). Nevertheless, when it is grown on glycerol it utilizes $\left({ }^{14} \mathrm{C}\right)$ acetate with ease (Edson et al. 1959).

A small amount (0.1-0.3 m-mole) of steam-volatile acid identified as acetic acid appeared in the medium when Mycobacterium butyricum grew on glycerol. When a correction is made for this endogenous acetate, the rate of disappearance of acetate was shown by an experiment in which 8-m-mole acetate were added to the glycerol-containing medium before inoculation. After incubation for 8 days $1.1 \mathrm{~m}$-mole of added acetate remained in the medium and none was left on the 11th day.

Table 4 shows the effect of added acetate on growth and on keto acid excretion. The lower concentrations of acetate $(2-6 \mathrm{~m}-\mathrm{mole} / 100 \mathrm{ml}$.) did not affect growth significantly but increased the excretion of pyruvic acid and diminished that of $\alpha$-oxoglutaric acid. The higher concentrations of acetate (7-10 m-mole/100 ml.) enhanced growth and the yield of $\alpha$-oxoglutaric acid. At $10 \mathrm{~m}$-mole acetate $/ 100 \mathrm{ml}$. the change in the keto acid excretion appears to have occurred at the expense of pyruvic acid.

Table 4. The effect of adding acetate to the defined medium

$100 \mathrm{ml}$. of medium containing $3.0 \mathrm{~g}$. glycerol and $0.1 \mathrm{~g}$. $\left(\mathrm{NH}_{4}\right)_{2} \mathrm{SO}_{4} \cdot 2 \mathrm{~N}$-sodium acetate solution was added aseptically. Period of incubation: 14 days.

$\begin{array}{ccccc}\begin{array}{c}\text { Acetate } \\ \text { added } \\ \text { (m-mole) }\end{array} & \begin{array}{c}\text { Final } \\ \text { pH } \\ \text { value }\end{array} & \begin{array}{c}\text { Bacterial } \\ \text { growth } \\ \text { (mg. dry wt.) }\end{array} & \begin{array}{c}\alpha \text {-Oxoglutaric } \\ \text { acid } \\ \text { (m-mole) }\end{array} & \begin{array}{c}\text { Pyruvic } \\ \text { acid } \\ \text { (m-mole) }\end{array} \\ 0 & 6 \cdot 5 & 143 & & \\ 2 & 6 \cdot 5 & 148 & 0 \cdot 6 & 0 \cdot 4 \\ 4 & 7 \cdot 1 & 144 & 0 \cdot 2 & 0 \cdot 7 \\ 5 & 7 \cdot 3 & 154 & 0 \cdot 3 & 0 \cdot 6 \\ 6 & 7 \cdot 3 & 140 & 0 \cdot 5 & 1 \cdot 1 \\ 7 & 7 \cdot 2 & 206 & 1 \cdot 0 & 1 \cdot 6 \\ 8 & 6 \cdot 6 & 201 & 2 \cdot 2 & \mathbf{1} \cdot 6 \\ 10 & 6 \cdot 0 & 249 & 6 \cdot 6 & 0 \cdot 2\end{array}$

Synthesis of amino acids from $\left(2-{ }^{14} \mathrm{C}\right)$ acetate and $\left({ }^{14} \mathrm{C}\right)$ bicarbonate

Mycobacterium butyricum was grown in $\mathbf{3 0} \mathrm{ml}$. defined medium containing 3.0 g. non-isotopic glycerol and $0 \cdot 4 \mathrm{~g}$. ammonium sulphate $/ 100 \mathrm{ml}$. The culture flask ( $100 \mathrm{ml}$.) was attached to a pump by means of which a stream of $\mathrm{CO}_{2}$-free air was drawn through the apparatus and respired $\mathrm{CO}_{2}$ was trapped in a 
bubbler containing $3 \mathrm{~N}-\mathrm{NaOH}$ solution. The flask was provided with a glassstoppered side-arm through which sterile solutions of ${ }^{14} \mathrm{C}$-containing substrates could be added to the medium.

Sodium $\left({ }^{14} \mathrm{C}\right)$ bicarbonate. A small volume $\left(0.4 \mathrm{ml}\right.$.) of $0.5 \mathrm{M}$ sodium $\left({ }^{14} \mathrm{C}\right)-$ bicarbonate solution (sterilized by filtration) with a specific activity of $9.23 \times 10^{6}$ counts $/ \mathrm{min}$. $/ \mathrm{m}$-mole was added to the medium of the second, third, fourth and fifth days after inoculation. Aeration was intermittent in order that some ${ }^{14} \mathrm{CO}_{2}$ should remain in the flask during the greater part of the experiment.

The organisms were removed on the sixth day, dried at $105^{\circ}$, defatted and hydrolysed in acid (see Methods). The amino acids derived from the somatic proteins were separated by paper chromatography and radioautographs were prepared. The radioactive areas of the paper were located by reference to the radioautograph and the spots cut out. These were mounted on a holder which exposed $6.3 \mathrm{~cm} .^{2}$ of paper and the radioactivity from both sides of the paper disks were counted under a thin end-window Geiger-Müller tube. Sufficient counts were taken to give a standard error of counting of $\pm 3 \%$. The mean counts for the two sides are recorded in Table 5 , there being no significant differences between the two counts. Radioactivity was detected in the amino acids in the culture filtrates but the concentration of amino acids was too low to permit measurement of the radioactivity.

Table 5. The isotope content of amino acids formed in the presence of $\left({ }^{14} \mathrm{C}\right)$ bicarbonate and $\left(2-{ }^{14} \mathrm{C}\right)$ acetate

The counts/minute have been corrected for background.

\begin{tabular}{lcc}
\multicolumn{1}{c}{ Amino acid } & $\begin{array}{c}\left({ }^{14} \mathrm{C}\right) \text { Acetate } \\
\text { (counts/min.) }\end{array}$ & $\begin{array}{c}\left({ }^{14} \mathrm{C}\right) \mathrm{Bi}- \\
\text { carbonate } \\
\text { (counts/min.) }\end{array}$ \\
Diaminopimelic acid & 33 & 45 \\
Aspartic acid & 91 & 148 \\
Glutamic acid & 316 & 247 \\
Serine & 15 & 11 \\
Glycine & 16 & 41 \\
Threonine & 53 & 74 \\
Alanine & 62 & 0 \\
Tyrosine & 9 & 0 \\
Lysine & 51 & 47 \\
Arginine & 57 & 208 \\
Proline & 93 & 97 \\
Leucine +isoleucine & 116 & 41
\end{tabular}

Sodium $\left({ }^{2-14} \mathrm{C}\right)$ acetate. On the first and fourth days after inoculation $0.9 \mathrm{ml}$. $\left(\mathbf{1} \cdot 25 \mathrm{~m}\right.$-mole) of an autoclaved solution of $\left(2^{-14} \mathrm{C}\right)$ acetate (specific activity $6 \times 10^{5}$ counts $/ \mathrm{min}$. $/ \mathrm{m}$-mole of $\left(2-{ }^{14} \mathrm{C}\right)$ acetate $)$ was added to the medium. The apparatus was flushed with $\mathrm{CO}_{2}$-free air at least three times daily to remove as much respiratory $\mathrm{CO}_{2}$ as possible and the bacteria collected on the sixth day. They were hydrolysed and radioautographs of the amino acids prepared as before. The counts of the paper chromatograms are given in Table 5 .

The most heavily labelled of the amino acids formed by cells grown in the 
presence of $\left({ }^{14} \mathrm{C}\right)$ bicarbonate were glutamic acid, arginine, aspartic acid and proline. No radioactivity was detected in the alanine spot. The distribution of ${ }^{14} \mathrm{C}$ from acetate led to the heaviest labelling in glutamic acid; next in order were leucine + isoleucine, aspartic acid and proline. In this case alanine was labelled.

These experiments show that Mycobacterium butyricum utilizes carbon dioxide and the methyl group of acetate to form certain amino acids whose carbon skeletons are known to be derived from intermediates of the citric acid cycle in other organisms. The relatively high count of arginine formed in the presence of ${ }^{14} \mathrm{CO}_{2}$ indicates that carbon dioxide fixation takes place by well-established pathways. The labelling of glycine and serine has a particular interest. The isotope content of both was low when the ${ }^{14} \mathrm{C}$ was derived from $\left({ }^{2-14} \mathrm{C}\right)$ acetate, but when it was derived from ${ }^{14} \mathrm{CO}_{2}$ the glycine was more heavily labelled than the serine. The absence of isotopic equilibrium in this case could be explained if the glycine were formed directly from $\left(1-{ }^{14} \mathrm{C}\right) \mathrm{gly}$ oxylate. This is possible because $\boldsymbol{M}$. butyricum contains isocitritase (Morrison \& Wright, 1958) and ${ }^{14} \mathrm{CO}_{2}$ is fixed in the requisite carboxyl group of isocitrate (Edson et al. 1959).

\section{DISCUSSION}

Traces of keto acids have been found in defined media on which tubercle bacilli were grown (Boissevain, 1943; Yonemura \& Iizuka, 1955a), the quantities being much smaller than those accumulated by Mycobacterium butyricum. On the other hand, Pseudomonas fluorescens excretes larger quantities of $\alpha$-oxoglutaric acid than $\boldsymbol{M}$. butyricum (Lockwood \& Stodola, 1946) but under appropriate conditions its behaviour closely resembles that of $\boldsymbol{M}$. butyricum. With $\boldsymbol{P}$. fuorescens strain $\mathrm{KB}_{1}$, Kogut \& Podoski (1953) found no $\alpha$-oxoglutaric acid in the medium unless the ratio of carbon (succinate) to nitrogen (ammonium ions) was made very large. Thus the excretion of keto acids is evoked in both organisms by restricting the available nitrogen supply relative to that of carbon (see Tables 2 and $\mathbf{3}$ ).

Free amino acids, especially glutamic acid, are released into the medium during the growth of tubercle bacilli on media which contain ammonium salts (Pauletta \& Defranceschi, 1952; Yonemura \& Iizuka, 1955b; Shoji, Yamagarni \& Mori, 1957). This appears to be due partly to breakdown of the organisms in the stationary phase and partly to amino acid excretion in earlier phases of culture. Dagley \& Johnson (1956) have related the excretion of free amino acids to particular growth phases of Escherichia coli and other organisms. Although this has not been done with Mycobacterium butyricum, it seems unlikely that the release of amino acids is due solely to autolysis in experiments which last 11 days (cf. Fig. 1 and Table 3). Amino acids were not released in significant amounts at low levels of nitrogen nutrition; and when they were released at high levels of nitrogen nutrition there was a reciprocal relation with keto acid excretion. This relation could be explained if the citric acid cycle has a major role in the synthesis of amino acids. The distribution of ${ }^{14} \mathrm{C}$ amongst the somatic acids supports this view (Table 5). Aspartic and glutamic acids, 
which are known to be most intimately associated with the citric acid cycle, were heavily labelled and members of their postulated families (diaminopimelic acid-lysine-threonine-isoleucine and arginine-proline respectively) were also radioactive (cf. Roberts et al. 1957).

The relevant flow of carbon in the citric acid cycle during growth of $M$ ycobacterium butyricum in the defined medium may be represented by the following scheme which neglects the oxidative function of the cycle.

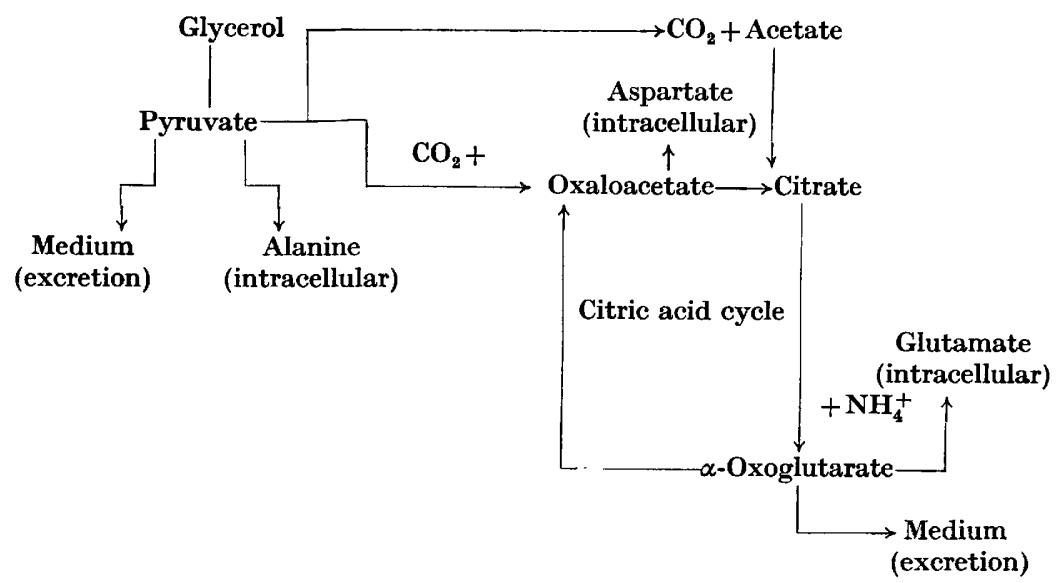

So long as cellular constituents are synthesized at a rate which is at least equal to the rate of carbon influx from glycerol, keto acids should not be excreted into the medium. The ammonia content of the medium will be a limiting factor in protein synthesis. Hence keto acid accumulation will not be expected in the early stages of growth even in a nitrogen-poor medium. If the culture continues to metabolize glycerol after it has attained maximum growth, or if the rate of glycerol breakdown exceeds the capacity for cell component synthesis during growth, carbon could flow from the cycle to the exterior either as keto acid or as amino acid, depending on the concentration of ammonia present in the medium contemporaneously.

The experimental observations are consistent with this interpretation. The accumulation of $\alpha$-oxoglutaric acid occurs late in the growth of Mycobacterium butyricum on a medium with a high glycerol:ammonia ratio and continues after maximum growth has been attained (Fig. 2); the addition of acetate to a glycerol-containing medium increases the outflow of carbon as keto acids (Table 4); and diminution of the glycerol:ammonia ratio in the medium suppresses the excretion of keto acids but leads to increased excretion of amino acids (Table 3) amongst which glutamic and aspartic acids are prominent. The excretion of pyruvic acid could be attributed to withdrawal from the pyruvate pool, especially in the presence of added acetate which might spare the direct oxidation of pyruvate; on the other hand, the excreted pyruvic acid might represent a withdrawal of oxaloacetate from the cycle, since oxaloacetate is readily broken down by a $\alpha$-carboxylase known to be present in acid-fast bacteria (Morrison, 1956). 
Acknowledgement is made to the Royal New Zealand Air Force for financial assistance, and to Professor N. L. Edson for his constant advice and encouragement.

\section{REFERENCES}

Borssevain, C. (1943). Survival of tubercle bacilli in solutions containing glycerol or its oxidation products. Proc. Soc. exp. Biol., N.Y. 54, 342.

Dagley, S. \& Johnson, A. R. (1956). Appearance of amino acids and peptides in culture filtrates of micro-organisms growing in mineral salt media. Biochim. Biophys. Acta, 21, 270.

Dent, C. E. (1948). A study of the behaviour of some sixty amino-acids and other ninhydrin reacting substances on phenol-' collidine' filter-paper chromatograms, with notes as to the occurrence of some of them in biological fluids. Biochem. $J$. 43, 169.

Drea, W. F. \& Andrejew, A. (1953). The Metabolism of the Tubercle Bacillus. Illinois: Charles C. Thomas.

Edson, N. L. \& Hunter, G. J. E. (1943). Respiration and nutritional requirements of certain members of the genus Mycobacterium. Biochem. J. 37, 563 .

Euson, N. L., Hunter, G. J. E., Kulka, R. G. \& Wright, D. E. (1959). The intermediary metabolism of glycerol in Mycobacterium butyricum. Biochem. $J$. (in the Press).

El Hawary, M. F. S. \& Thompson, R. H. S. (1953). Separation and estimation of blood keto acids by paper chromatography. Biochem. J. 53, 563.

Friedemann, T. E. \& Haugen, G. E. (1943). Pyruvic acid. II. The determination of keto acids in blood and urine. J. biol. Chem. 147, 415.

GaLE, E. F. (1947). The assimilation of amino acids by bacteria. 1. The passage of certain amino-acids across the cell wall and their concentration in the internal environment of Streptococcus faecalis. J. gen. Microbiol. 1, 53.

Harrow, B., Stone, G. C. H., Borek, E., Wagriech, H. \& Mazur, A. (1944). Laboratory Manual of Biochemistry. U.S.A.: W. Saunders and Co.

Hiller, A., Plazin, J. \& van Slyke, D. D. (1948). A study of conditions for Kjeldahl determination of nitrogen in proteins. Description of methods with mercury as catalyst, and titrimetric and gasometric measurements of the ammonia formed. J. biol. Chem. 176, 1401.

Hunter, G. J. E. (1953). Acid formation in cultures of Mycobacterium butyricum. J. Bact. 66, 676.

Kogut, M. \& Podoski, E. P. (1953). Oxidative pathways in a fluorescent Pseudomonas. Biochem. J. 55, 800.

LAMBert, M. \& Neish, A. C. (1950). Rapid method for estimation of glycerol in fermentation solutions. Canad. J. Res. B, 28, 83.

Lockwood, L. B. \& Stodola, F. H. (1946). Preliminary studies on the production of $\alpha$-ketoglutaric acid by Pseudomonas fuorescens. J. biol. Chem. 164, 81.

Morrison, N. E. (1956). Oxidation of malate by Mycobacterium smegmatis. Proc. Univ. Otago Med. Sch. 34, 23.

Morrison, N. E. \& Wright, D. E. (1958). Isocitratase activity in Mycobacterium butyricum. Proc. Univ. Otago Med. Sch. 36, 1, 15.

Pauletta, G. \& Defranceschi, A. (1952). Studies on the amino acid metabolism of Mycobacterium tuberculosis. I. Primary investigation by paper chromatography. Biochim. Biophys. Acta, 9, 271.

Rem, R. L. \& Lederer, M. (1952). Separation and estimation of saturated $\mathrm{C}_{2}-\mathrm{C}_{7}$ fatty acids by paper partition chromatography. Biochem. J. 50, 60.

Roberts, R. B., Abelson, P. H., Cowie, D. B., Bolton, E. T. \& Britten, R. J. (1955). Studies of biosynthesis in Escherichia coli. Publ. Carneg. Instn, no. 607 . 
Shoji, K., Yamagami, A. \& Mori, T. (1957). Studies on the amino acid metabolism of Mycobacterium tuberculosis. I. Utilisation of some nitrogenous substances and accumulation of free glutamic acid in bacterial cells. Med.J. Osaka Univ. 7, 787.

Yonemura, T. \& Irzuka, M. (1955 $a)$. Studies on the metabolism of amino acids in tubercle bacilli. I. The changes of free amino acids in liquid synthetic media following the growth of bacilli. Jap. J. Tuberc. 3, 6 .

Yonemura, T. \& Irzuka, M. (1955 b). Studies on the metabolism of amino acids in tubercle bacilli. II. On the mechanism of the appearance of free amino acids in the medium. Jap. J. Tuberc. 3, 22.

(Received 24 November 1958) 